\title{
LA MASONERIAA Y SU INFLUENCIA SOCIAL EN EL CASTELLÓN DE FINALES DEL XIX
}

\author{
FREEMASONRY AND ITS SOCIAL INFLUENCE IN \\ CASTELLÓN AT THE END OF THE 19TH CENTURY
}

\author{
Francisco Miguel Jimeno Yepes \\ Licenciado en Humanidades- Universitat Jaume I
}

\section{RESUMEN}

Durante el Sexenio la ciudad de Castellón comenzó a tener talleres masónicos. En la Restauración, y especialmente en la década de 1880, la organización estructural de la masonería llegó a ser compleja, destacando las logias bajo la obediencia del Gran Oriente Nacional de España. Fue entonces cuando estos actores se convirtieron en protagonistas de las redes sociales de la ciudad e incluso tuvieron una participación directa en política local dentro de las filas del republicanismo, aunque este punto no es tratado en el artículo. Controlaron centros de socialización, como es el caso del Casino de Artesanos. Contaron con publicaciones que les apoyaron y tuvieron una publicación propiamente masónica, La Razón, surgida como defensa de los elementos anti-masónicos evidenciados desde La Verdad, entre otras publicaciones. Los resultados más plausibles fueron la Exposición de Castellón de julio de 1887 y la Exposición de instrucción primaria de Salinas.

Palabras clave: masonería, redes sociales, Castellón, Restauración

\begin{abstract}
The city of Castellón began to hold Masonic workshops during the period called "Sexenio Revolucionario". In the course of the Restoration, and especially in the 1880s, the structural organisation of Freemasonry became complex, specially the lodges under the auspices of the Great National Orient of Spain. It was then that these actors became the main protagonists of the city's social networks and even participated directly in local politics within republicanism ranks, although this is not discussed in the article. They controlled social centres, such as the "Casino de Artesanos". They relied on publications that supported them and had a proper Masonic publication, "La Razón", that emerged as a defence against anti-Masonic elements evidenced in "La Verdad", amongst other publications. The more plausible results were the "Exposición de Castellón" in July 1887 and the "Exposición de Salinas" of primary instruction.
\end{abstract}

Keywords: Freemasonry, social networks, Castellón, Restoration 
La masonería puede ser vista desde una triple perspectiva: desde la de los propios masones, que van a defender sus planteamientos; desde la de los detractores, que normalmente defenderán la tesis del complot; y desde la planteada por los profanos, por ejemplo los historiadores.' Con este planteamiento, el estudio de la masonería no se centra sólo en narrar los acontecimientos de las logias, sino que debemos ir más allá. El que existan unos detractores implica una acción de los masones fuera de las logias, por lo que pasamos de estudiar el fenómeno masónico como algo hermético a tratarlo en su interacción con la sociedad que lo rodea, y por tanto le damos una significación social como grupo y una producción cultural derivada de la interactuación de sus elementos endógenos junto con sus planteamientos filosó- ficos e ideológicos y su plasmación en la interactuación con el mundo profano, los elementos exógenos. De aquí se deriva, por consiguiente, una producción cultural. La masonería tendría una función y surgiría de la necesidad de unos actores sociales que reconocerían en esta forma de socialización una vía para desarrollar sus inquietudes.

Desde el Sexenio Castellón ha dispuesto de talleres masónicos, y coincide en un momento en el que el republicanismo va a ir cobrando cada vez más importancia dentro de la política local. La masonería no sólo va a tener poco a poco más relevancia en política, con masones dentro de las filas del republicanismo, sino que va a ir expandiendo su influencia a través de determinadas instituciones que formaban parte de la red social de Castellón, como el Casino de Artesanos. Buscar una explicación a cómo ha sucedido es una tarea complicada: la documentación conservada es escasa, y si tenemos en cuenta la propia naturaleza de las logias, en las que no estaban permitidas las discusiones políticas, podríamos incluso dudar de esto. Sin embargo, dedicando tiempo al análisis de publicaciones de la época nos percatamos de la relevancia del elemento masónico.

1 Olivia Salmón-Monviola, La palabra de paso - Identidades y transmisión de la masonería de Madrid (1900-1936), en Ediciones Idea, Colección Escuadra y Compás, Santa Cruz de Tenerife, 2008, pp. 27-29. 
En este artículo me voy a centrar en la repercusión social que tuvo la masonería a su paso por Castellón. Voy a comenzar con la descripción de las logias de las que se tiene conocimiento hasta el momento, comprobar la complejidad estructural que alcanzó y analizar los principales medios profanos que utilizó para llevar a cabo sus fines. ${ }^{2}$

\section{Las logias masónicas en la ciu- dad de Castellón}

La existencia de logias en Castellón estuvo ligada a la historia de la masonería en España, y sobre todo a la historia de sus obediencias. En cuanto a la documentación conservada, la suerte es muy desigual. Toda la documentación de las logias de Castellón se encuentra en el legajo 752-A expedientes 1 al 18 del Centro Documental de la Memoria Histórica, Sección Masonería, de Salamanca. En este mismo archivo podemos consultar la documentación de sus grandes orientes.

Hay una referencia a la posible existencia de una logia masónica a principios del siglo XIX durante el reinado de Fernando $\mathrm{VII}^{3}{ }^{3}$ sin embargo no es relevante para este artículo, dada su distancia temporal con el período tratado y la imposibilidad de poder demostrar su existencia por no haber evidencia documental directa.

Durante el Sexenio se va a producir en España un importante desarrollo de la masonería, con un aumento considerable de sus efectivos y una importante reorganización al levantarse su prohibición. ${ }^{4}$ No se puede descartar, no obstante, la posible presencia de logias anteriores a éstas auspiciadas bajo otros orientes, nacionales o extranjeros, 0 la existencia de masones naturales

2 Para profundizar en más aspectos de la masonería castellonense, consultad mi trabajo de investigación Masonería en Castellón a finales del siglo XIX - Influencia en la vida social y política de los primeros años de la Restauración, depositada en el Departamento de Geografía e Historia de la UJl. Se encuentra una actualización de las logias masónicas presentes en la provincia de Castellón desde el Sexenio hasta finales del siglo XIX con un análisis en más profundidad de los aspectos sociales y políticos.

3 En la página web de la Respetable Logia Manuel Fabra, en activo en Castellón, se habla de Miguel José NEBOT CLOFENTE, apodado "El Frare", que llevó a cabo un intento frustrado de reinstaurar la Constitución de 1812. http://www.rlmanuelfabra.org/historia.htm

4 J. Ignacio Cruz, Masonería y educación en la Il República Española, en Instituto de Cultura Juan Gil-Albert, Valencia, 1993, p. 21. 
de Castellón en otras zonas de la Península.

La logia Justicia, $n^{\circ} 21,{ }^{5}$ se encontraba bajo los auspicios del Gran Oriente de España y debió formarse en el primer semestre de 1871. No sabemos más que el nombre y el número que se le asignó dentro de la obediencia a la que pertenecía, dato que podemos encontrar en el Boletín Oficial de su gran oriente. La última pista es su aparición en una lista de logias del Gran Oriente de España con fecha de 1 de junio de 1873. No hay cuadros lógicos ni ningún tipo de documento. Leyendo los boletines conservados tampoco encontramos más rastros.

La logia Castulonense, $n^{\circ} 36,{ }^{6}$ es la otra logia documentada del Sexenio y estaba auspiciada bajo el Gran Oriente Nacional de España. Fue constituida el 8 de junio de 1870. El listado en el que se recoge esta logia contiene los talleres de su jurisdicción existentes en actividad en 1876, por lo que podemos pensar que al menos hasta ese año estuvo funcionando.

A pesar de conocer la existencia de estas dos logias, es muy complicado determinar su relación con otras posteriores dentro de la misma obediencia debido a la falta de documentación.

\subsection{Las logias bajo los aus- picios del Gran Oriente Na- cional de España a finales del siglo $X^{\prime} X^{7}$}

Después de la logia Casturolense encontramos bajo el Gran Oriente Nacional de España a la

5 Boletín Oficial del Gran Oriente de España, n 6 de 15 de julio de 1871, p. 6. También va a aparecer en listados de Logias del Oriente a partir del 15 de mayo de 1872. Su primera aparición corresponde a una comunicación del Gran Oriente de España en la que enumeraba la $1^{a}$ sección de los Talleres Masónicos de su obediencia (del 1 al 50), documentados con arreglo a Constituciones y confirmados en sus derechos y privilegios.

6 Boletín Oficial del Serenísimo Gran Oriente Nacional de España, núm. 187 de 15 de abril de 1895. Confecciona un listado de las logias que pertenecen y pertenecieron a la obediencia, teniendo en cuenta las reformas de 1876 y 1893.

7 Conviene aclarar que el Gran Oriente Nacional de España es una obediencia que sufrió una escisión con la muerte del Gran Maestro y Gran Comendador Marqués de Seoane a principios de 1887. El Vizconde de Ros crearía una nueva obediencia con el mismo nombre, y tendremos dos con la misma denominación de Gran Oriente Nacional de España. Las logias de Castellón se van a mantener fieles a su gran oriente, con José María Pantoja como Gran Comendador y Gran Maestre y Caballero de Puga como Gran secretario hasta 1896, fecha en la que se acaba la documentación de las logias de Castellón en el siglo XIX. 
logia Tres Estrellas, $\mathrm{n}^{\circ}$ 135. De ella se conserva la Solicitud de Carta Constitutiva, ${ }^{8}$ de 9 de Diciembre de 1879, al Gran Oriente Nacional de España y diversos cuadros lógicos. ${ }^{9}$ La logia tuvo problemas en sus inicios debido a que había hermanos procedentes de otras obediencias que querían convalidar sus grados con los del Gran Oriente Nacional de España, ${ }^{10}$ lo que quiere decir que algunos provenían de otras obediencias. ${ }^{11}$ La última noticia de Tres Estrellas la encontramos en el Boletín Oficial del gran oriente. Será la petición por parte del orien- te del cuadro lógico, de las cuentas del último semestre, de los estados de situación y la memoria de los trabajos realizados en $1891 .{ }^{12}$ Por lo tanto, el taller siguió funcionando al menos hasta principios de 1892.

Tres Estrellas creó un capítulo asociado para albergar a los grados del $4^{\circ}$ al $18^{\circ}, 13$ que se llamó capítulo Tres Estrellas, $\mathrm{n}^{\circ} 28,{ }^{14}$ funcionando de forma conjunta tanto el taller como el capítulo. ${ }^{15}$ En un principio albergó sólo los grados capitulares de Tres Estrellas; sin embargo, a medida que se fueron formando otras logias ${ }^{16}$ sus grados

8 Con fecha de 3 Thebet (Diciembre) 5879, aparece el nombre de Tres Luces en vez de Tres Estrellas.

9 Los Cuadros Lógicos son de las siguientes fechas: 9 Thebet 1879, 16 Thamur 1880, 10 Avar 1882, 17 Thebet 1884, 9 enero 1886 y un último Cuadro sin fecha, pero no anterior a 31 diciembre de 1887 .

10 Libro de Actas del Grande Oriente Nacional de España, sesión de 25 de enero de 1880.

11 Durante mi investigación sobre las relaciones internacionales de la masonería española e inglesa he visto la evolución de los grandes orientes y cómo la existencia de obediencias españolas y la crisis del Gran Oriente Lusitano Unido propició el movimiento de masones bajo obediencias portuguesas a Grandes Orientes españoles. También puede evidenciar la rivalidad entre las obediencias nacionales.

12 Boletín Oficial del Serenísimo Grande Oriente Nacional de España, n 114 de 30 de marzo de 1892, p. 2.

13 Boletín Oficial del Serenísimo Grande Oriente Nacional de España, $n^{\circ} 4$ de 31 agosto de 1887, p. 2.

14 No se puede precisar la fecha de creación, aunque en la lista de logias antes referida aparece que estuvo creado a la vez que el taller y con el nombre de Capítulo Integridad y no Tres Estrellas.

15 Boletín Oficial del Serenísimo Grande Oriente Nacional de España, n 12 de 30 de diciembre de 1887 , p. 4. 
capitulares se fueron incorporando a éste. ${ }^{17}$

El capítulo pasaría a llamarse capítulo Integridad, $\mathrm{n}^{\circ} 28 .{ }^{18}$ De este nuevo capítulo se conservan dos cuadros lógicos, uno de 1 de enero de 1889 y otro de 31 de diciembre de 1895. ${ }^{19}$ Además, en el Boletín Oficial del Serenísimo Grande Oriente Nacional de España aparece publicado su Reglamento. ${ }^{20}$ Fernando Gasset (Velarde) sería Atisartha de este capítulo y presentó su dimisión en Agosto de 1889, ${ }^{21}$ siendo designado por el oriente para reemplazarle el hermano Ascensio Castells (Medi) grado $25 .^{22}$

La logia Tres Estrellas también propició la creación de otras dos logias, actuando como logia madre. El Progreso, $\mathrm{n}^{\circ} 213$, y Esperanza $V, \mathrm{n}^{\circ} 214$, fueron constituidas de forma correlativa el 4 de julio de 1886 y de ellas se conservan algunos cuadros lógicos, así como las Cartas Constitutivas y en el caso de El Progreso también el Acta de Constitución.

Por la documentación conservada, Esperanza $V$ estuvo funcionando hasta 1889, sin embargo, en el boletín del oriente encontramos que siguió en activo hasta principios de 1892 por lo menos. ${ }^{23}$

En cuanto a El Progreso el último cuadro lógico es de enero de

16 Esperanza V, núm. 214, El Progreso, núm. 213, y Luz del Valle, núm. 261.

17 Boletín Oficial del Serenísimo Grande Oriente Nacional de España, $\mathrm{n}^{\circ} 13$ de 15 de enero de 1888 , p. 2.

18 La aprobación del cambio de título aparece publicada en el Boletín Oficial del Serenísimo Grande Oriente Nacional de España, n 21 de 15 de mayo de 1888, p. 2. En el listado de logias de 1895 le da como fecha de constitución el 14 de diciembre de 1879, el mismo que para la logia Tres Estrellas, pero no tiene sentido visto lo expuesto.

19 Teniendo en cuenta la fecha del último Cuadro Lógico se supone que se debieron realizar elecciones para los cargos del Capítulo, lo que demuestra continuidad en su funcionamiento y que por lo tanto estuvo en activo al menos un año más. Si vemos de dónde se nutre podemos suponer también que en 1896 debió haber aún en activo alguna logia simbólica en Castellón.

20 Boletín Oficial del Serenísimo Grande Oriente Nacional de España, $n^{\circ} 28$ de 30 agosto de 1888 , p. 4.

21 Seguramente para ser presidente del Capítulo Provincial.

22 Boletín Oficial del Serenísimo Grande Oriente Nacional de España, $\mathrm{n}^{\circ} 52$ de 30 de agosto de 1889, p. 1.

23 Petición por parte del oriente de Cuadro Lógico, Cuentas del último semestre, Estados de situación y memoria de los trabajos realizados en 1891, Boletín Oficial del Serenísimo Grande Oriente Nacional de España, ${ }^{\circ} 114$ de 30 de marzo de 1892, p. 2. 
$1895,{ }^{24}$ lo que indica que estuvo en activo por lo menos hasta este año. Sin embargo, no lo hizo de forma continuada. ${ }^{25}$ Hay, por tanto, una laguna entre el cuadro lógico de 27 de Diciembre de 1888 y el siguiente, de enero de 1895, y también entre la aparición en marzo de $1892^{26}$ en el Boletín Oficial y la siguiente de diciembre de 1893. La cuestión sería poder determinar el periodo de inactividad y en la medida de lo posible también las causas. En la prensa de Castellón encontramos alguna referencia a El Progreso; la última en La Hoja Suelta de 1 de noviembre de 1891, en la que se mencionaba una tenida el 24 de octubre de ese año. ${ }^{27}$ Comenzó un periodo de restauración a finales de 1893 y a finales de 1894 aún no se encontraba en completo funcionamiento, como indica una comunicación con el gran oriente. ${ }^{28}$

El gran oriente también autorizó a este taller a restaurar, con los grados capitulares del mismo, el capítulo Integridad, núm. $28 .^{29}$ En mayo de 1895, dos comunicados en el boletín decretaban la reconstrucción del capítulo y nos permite ver su situación. ${ }^{30}$ El único cuadro de capítulo Integridad después de su restauración es de 31 de diciembre de 1895, sin embargo debió existir por lo menos uno anterior, tal

24 Se conservan Cuadros Lógicos consecutivos de 1886 a 1888 y se produce un salto hasta 1895, año del que sólo se conserva un Cuadro Lógico con fecha de 15 de enero.

25 Consultando el Cuadro Lógico de 15 de enero de 1895, el último ascenso de grado se produjo en de febrero de 5890, por lo que podemos asegurar que hubo poca actividad desde entonces.

26 Boletín Oficial del Serenísimo Grande Oriente Nacional de España, n 114 de 30 de marzo de 1892, p. 2.

27 En la tenida, según la publicación, se acordó algún tipo de acción en contra de los redactores de ésta. En La Hoja Suelta, n 10, de 1 de noviembre de 1891, p. 2.

28 Boletín Oficial del Serenísimo Grande Oriente Nacional de España, $\mathrm{n}^{\circ} 180$ de 30 de diciembre de 1894, p. 2.

29 Boletín Oficial del Serenísimo Grande Oriente Nacional de España, n 180 de 30 de diciembre de 1894, p. 5.

30 Documento 1) Boletín Oficial del Serenísimo Grande Oriente Nacional de España, n 190 de 30 de mayo de 1895, p. 2. La comunicación al Capítulo continúa, determinando los pasos a seguir para su reconstrucción. Documento 2) Boletín Oficial del Serenísimo Grande Oriente Nacional de España, n 190 de 30 de mayo de 1895, p. 4. El decreto al que se hace mención corresponde a una medida para vigilar el exacto cumplimiento de las obligaciones con el oriente en el próximo solsticio estival. 
y como indica el boletín de agosto de $1895 .^{31}$ En este mismo número también encontramos una comunicación a El Progreso sobre su hoja de trabajos del mes de Julio. ${ }^{32}$ Hay referencias a capítulo Integridad y a Progreso en el último número del boletín, de agosto de $1896 .{ }^{33}$

Antes de acabar esta sección dedicada al Gran Oriente Nacional de España hay que señalar la existencia del Capítulo Provincial de Castellón. El primer indicio de este capítulo lo encontramos en el libro de actas de su oriente, en la concesión de Carta Constitutiva a Tres Estrellas. En ella se nombraba a su Venerable Maestro como presidente del capítulo provincial. ${ }^{34}$ Por tanto, debemos suponer su existencia antes del 14 de diciembre de 1879. La siguiente aparición también la encontramos en el libro de actas, en la que su presidente, José Lombarte, envió una petición a la máxima autoridad del gran oriente. ${ }^{35}$ La siguiente referencia aparece en el $n^{\circ} 5$, de fecha 15 de septiembre de 1887, en una comunicación a Esperanza V. ${ }^{36}$ Leyendo el Boletín Oficial del Serenísimo Grande Oriente Nacional de España hay referencias constantes del Capítulo Provincial de Castellón, siempre que comunicaba algo a todas las logias de Castellón que se encontraban dentro de su obediencia.

Las logias de la provincia de Castellón que se encontraban bajo los auspicios del Grande Oriente Nacional de España estaban sometidas a la jurisdicción de esta logia capitular, incluso las concesiones de grados capitulares debían pasar por ella. Una forma de mediar entre las logias era, por ejemplo, velar por la armonía y aunar asperezas entre los talleres de su jurisdicción, a la vez que normalizar y organizar la marcha de las nuevas logias,

31 Boletín Oficial del Serenísimo Grande Oriente Nacional de España, n 193 de 15 y 30 de agosto de 1895, p. 2.

32 Boletín Oficial del Serenísimo Grande Oriente Nacional de España, n. 193 de 15 y 30 de agosto de 1895, p. 3.

33 Boletín Oficial del Serenísimo Grande Oriente Nacional de España, $n^{\circ} .205$ de 15 y 30 de agosto de 1896, p. 3 . Se trata del último número de esta publicación, debido a la irrupción de la policía en el local de este gran oriente.

34 Carta Constitutiva a Tres Estrellas, nombrada anteriormente.

35 Libro de Actas del Grande Oriente de España, p. 24. La sesión es de mediados de 1880, sin poder precisar fecha exacta.

36 Boletín Oficial del Serenísimo Grande Oriente Nacional de España, n 5 de 15 de septiembre de 1887 , p. 4. 
dando así unidad a la Institución en la provincia. ${ }^{37}$ Se encuentra publicado su reglamento, ${ }^{38}$ aprobado por el capítulo el 20 de noviembre de 1888, en el boletín de 30 de enero de $1889, \mathrm{n}^{\circ} 38$.

Las comunicaciones entre 1889 y 1892 hacían referencia al cumplimiento de las obligaciones de los talleres y el capítulo con su gran oriente, especialmente en lo referente a la entrega de cuadros lógicos, estados de situación y memoria de los trabajos, así como los pagos de la suscripción del boletín. Pidió al capítulo provincial que exigiera su cumplimiento. La última aparición en el boletín, relacionada con este tema, sería el 30 de marzo de 1892. La situación que se estaba produciendo en Castellón era similar a la de muchos puntos de España.

Por un decreto del Gran Oriente Nacional de España con fecha de 15 de marzo de 1893 los capítulos provinciales pasaron a ser logias provinciales. ${ }^{39}$ Con este nombre es como aparece el capítulo provincial en el Boletín Oficial del Serenísimo Grande Oriente Nacional de Espa- ña, en una relación de logias con fecha de 15 de abril de 1895, y se le daba como fecha de constitución el 15 de marzo de 1893.

Su funcionamiento dependía de los talleres y del capítulo que se encontraban en su jurisdicción, ya que se nutría de los cargos más importantes de cada uno de ellos, por lo que el cese de actividad en estos se vio reflejado en su sostenimiento. La existencia de una logia reconstruida, Progreso, y un capítulo en reconstrucción, Integridad, no justificaría el funcionamiento de un capítulo provincial. De todas formas, con los sucesos acaecidos en 1896 en el Gran Oriente Nacional de España, la Logia Provincial de Castellón no habría existido más allá de este año.

\subsection{Logias bajo los auspi- cios del Gran Oriente de Es- paña y Gran Oriente Español a finales del siglo $\mathrm{XIX}$}

No podemos encontrar una relación entre la logia Justica, antes mencionada, y la logia Verdad, núm. 182, que la sigue cronológi-

37 Boletín Oficial del Serenísimo Grande Oriente Nacional de España, $\mathrm{n}^{\circ} 11$ de 15 de diciembre de 1887 , p. 2.

38 Lo firma como presidente Velarde (Fernando Gasset), grado 24, y como secretario Amadeo (Juan Martín Pich), grado 9. El certificado de aprobación por parte del GONE es de 14 de febrero de 1889

39 Boletín Oficial del Serenísimo Grande Oriente Nacional de España, n 137 de 15 de marzo de 1893, p. 6. 
camente como logia perteneciente al Gran Oriente de España y de la que simplemente poseemos el cuadro lógico de $1883 .{ }^{40} \mathrm{El}$ número de masones ascendía a 63 y un dato destacable es el gran número de militares que la componían. Abatió columnas entre final de 1887 e inicio de 1888.

Existen algunas coincidencias entre la logia Verdad y Perfecta Razón. Ambas son numeradas como 182 en el Gran Oriente Nacional de España y las fechas entre las que una abate columnas y la otra las levanta son muy similares.

Perfecta Razón es una de las logias de la que más datos poseemos siendo, sin embargo, la de más corta duración. Podemos datar tanto el momento en el que levanta sus columnas, el 31 de enero de 1888, como el momento en que las abate, sobre todo debido a problemas internos, para formar la logia Castalia, $n^{\circ} 91$. Durante su corta vida se en- contraró bajo el auspicio del Gran Oriente de España, del Gran Oriente Nacional de España del Vizconde de Ros y del Gran Oriente Español. ${ }^{41}$ Se encuentran bien documentados los problemas por los que pasó debido a su Venerable Maestro, ${ }^{42}$ José Baeza Méndez, ${ }^{43}$ y de como, ante la imposibilidad de su reconstrucción decidieron abatir columnas y construir una nueva, Castalia.

La logia Castalia levantó columnas el 1 de marzo de 1890.44 Todos los obreros del primer cuadro de este taller provienen de Perfecta Razón. El 15 de abril de 1890 aparecía como admitida en la federación de logias que era el Gran Oriente Español. ${ }^{45}$ Encontramos sólo referencias indirectas en el Boletín del Gran Oriente Español y en publicaciones locales y podemos pensar que estuvo funcionando hasta por lo menos 1892. ${ }^{46}$

Perfecta Razón y Castalia tuvieron una logia Capitular, llamada

40 Enviado a la logia Amor, núm. 20 de Madrid con fecha 8 de junio de 1883.

41 El 9 de enero de 1889 se forma el nuevo núcleo masónico y el 12 de mayo adopta el nombre de Gran Oriente Español. Olivia Salmón-Monviola, La palabra de paso - Identidades y transmisión de la masonería de Madrid (1900-1936), pp. 30 y 31.

42 Se basa en la carta de la logia Perfecta Razón al Gran Comendador del Gran Oriente Español, con fecha de 23 de Octubre de 1889, y en la extensa carta que manda a título personal Vicente Avinent a Miguel Morayta, con fecha de 10 de noviembre de 1889.

43 Fue Suspendido provisionalmente por faltas graves, Boletín Oficial del Gran Oriente Español, $\mathrm{n}^{\circ} 10$ de 15 de noviembre de 1889, p. 4.

44 Copia certificada con fecha 17 de marzo de 1890 de la sesión preparatoria de la logia Castalia, celebrada el 1 de marzo de 1890.

45 Boletín del Gran Oriente Español núm. 17 de 15 de abril de 1890, p. 4.

46 La Verdad, $\mathrm{n}^{\circ} 175$, de 10 de abril de 1892, p. 4. 
Capítulo Razón. El único documento conservado es la patente enviada desde el Supremo Consejo del Grado 33 del Gran Oriente Nacional de España para la creación del capítulo, con fecha 27 de septiembre de 1888, con el Vizconde de Ros como Gran Comendador. En la documentación de Perfecta Razón encontramos una carta con fecha de 23 de agosto de 1888 dirigida al Gran Comendador Vizconde de Ros pidiendo la Carta Constitutiva al Supremo Consejo del Grado 33 de una logia capitular. El 13 septiembre 1888 se envió una carta a Alfredo de Vega, Vizconde de Ros, relatando los cargos del capítulo y anunciando el pago de los títulos que quedaban por pagar. También en el expediente de Perfecta Razón se encontraba el cuadro lógico de formación del capítulo.

Debemos tener en cuenta que en el momento en que Morayta creó un nuevo oriente, Perfecta Razón cambió su adhesión, y por tanto también el capítulo. Esto quiere decir que el resto de noticias acerca de este capítulo lo encontramos en el Boletín Oficial de esta nueva obediencia. En el número 16, de 20 de marzo de 1890, aparecía dentro de la relación de talleres capitulares como Capítulo Razón, núm. 19.

La última aparición de este capítulo en el boletín es en el número 28 de 4 de febrero de 1891, en el que se recuerda a Razón, núm. 19, que debía elegir su representante para la Asamblea. Al igual que Castalia estuvo funcionando durante 1891, sin poder decir más.

\subsection{Conclusiones}

En este primera parte he tratado de enumerar las logias de la ciudad de Castellón durante el último tercio del siglo XIX. No he pretendido realizar una reconstrucción, sino de disponer de un elemento de base para poder tratar la repercusión de la masonería en la capital, permitiendo identificar y situar las diferentes logias que existieron. Hemos podido comprobar también su relación con el oriente al que estaban auspiciadas y de qué forma la evolución de las logias seguía una suerte similar a lo que sucedería a la masonería a nivel nacional.

Capítulo Integridad nos deja ver las dimensiones que tendría la masonería en la ciudad de Castellón. La existencia de un capítulo provincial, así como de una logia capitular y varias logias simbólicas, con una duración larga en el tiempo, nos hace pensar en una estructura compleja y por tanto nos da idea de la importancia que tuvieron los masones del Gran Oriente Nacional de España no solo en la ciudad de Castellón, sino también a nivel provincial.

Mediados y finales de la década de 1880 fue el momento de mayor presencia masónica, y fue cuando se notó en la sociedad su mayor influencia, como veremos reflejado en las publicaciones de la época. 


\section{LA SOCIABILIDAD MASÓNICA}

La principal dificultad para determinar el impacto de la masonería en la sociedad castellonense es la falta de información de lo que sucedía en las logias, ya que casi no sabemos qué se trataba en las tenidas. Los boletines oficiales de los grandes orientes nos pueden dar alguna idea. Otro de los recursos de los que disponemos son las publicaciones de la época.

Podemos clasificar a la prensa de la siguiente forma: masónica, antimasónica y paramasónica, dependiendo del posicionamiento ideológico con respecto a la Orden. ${ }^{47}$ Publicaciones como El Clamor de la Democracia, El Clamor de Castellón, El Escándalo, 48 La Bandera Laica, La Juventud, Cascarrita, durante un tiempo El Diario de Castellón, ${ }^{49}$ El Blua o Castalia, entre otras, tuvieron alguna relación con la masonería, ya que algunos de sus redactores o sus mismos directores fueron masones, por tanto serían consideradas paramasóni- cas. La Razón de Castellón fue una publicaciones masónica.

Publicaciones antimasónicas fueron La Plana Católica, 50 El Restaurador y La Verdad, y una que, no declarándose antimasónica, la combatiría en algunos de sus números, como es La Hoja Suelta. La única que no se ha conservado es El Restaurador. Estas publicaciones resultan ser una fuente bastante importante de información por su intento continuado de desprestigiar a la Orden y por su obsesión de desvelar el nombre de masones de Castellón. Sin embargo, también son una fuente que hay que analizar con cuidado, ya que muchas veces la información que publicaban resultaba imprecisa y otras la publicaban para ver la reacción de los masones y así sacar sus conclusiones.

La clasificación antes descrita no permite posicionar de forma cómoda una publicación que existió en la misma época que La Razón y La Verdad, ya que se situaría justo en medio de masones y antimasones, y

47 Esta clasificación de los medios de comunicación es muy utilizada por el Centro de Estudios Históricos de la Masonería Española. En Ventura Gayete, Empar Eugènia: Tres publicaciones y un debate: La bandera federal, La antorcha valentina y La verdad. En La Masonería en Madrid y en España del siglo XVIII al XXI, coordinador J. A. Ferrer Benimeli, Gobierno de Aragón Departamento de Educación, Cultura y Deporte. Gobierno de Aragón, 2004, p. 353.

48 Se comenta la redacción de una publicación con el título de El Escándalo, llevada a cabo por los redactores de El Clamor, que no querían ensuciar sus columnas, siguiendo a La Provincia. El Clamor de Castellón, $n^{\circ}$ 489, de 30 enero de 1890, p. 1.

49 Cuando estuvo bajo la dirección de Carlos Llinás.

50 Se dedicó a combatir a la masonería desde que se publicara la Encíclica Humanun Genum hasta que pasó a ser Órgano Oficial del Partido Católico Tradicionalista de la provincia. 
de hecho se enfrentaría con ambas publicaciones durante su corta existencia de 12 números. ${ }^{51}$ La $X$, que se presentaba como un periódico moral, de instrucción y de recreo, ${ }^{52}$ tenía entre el sector femenino a sus principales lectores. Su directora, Aurelia Mateo de Alonso, había pertenecido a la masonería y colaborado con Las Dominicales del Librepensamiento.

Además de con publicaciones, la masonería contó con alguna sociedad que le ayudó a llevar a cabo sus propósitos. Una de ellas fue el Casino de Artesanos, controlado durante varios años por masones, y con el que desarrollarían proyectos importantes, alguno de grandes dimensiones. Una vez la masonería casi se hubo extinguido en la capital, esta sociedad perdería protagonismo en la escena castellonense. Otra sociedad, pero en menor medida, relacionada con la masonería fue el Centro Democrático Instructivo, perteneciente al republicanismo progresista democrático de González Chermá. Podemos encontrar algún masón en su junta directiva, pero no fue una institución dedicada a proclamar las excelencias de la Orden y no será analizada en este artículo.

\subsection{La Razón, revista ma- sónica}

La revista La Razón es la única publicación declarada abiertamente masónica de las que nos encontramos en la capital. Se publicaría sin interrupción desde el 1 de marzo de 1889 al 4 de enero de 1891. La imprenta y la dirección para reclamaciones y remitidos sería la misma en la que se publicaba El Clamor de Castellón, publicación republicana. La redacción recaía sobre el masón Joaquín Martínez Barrajón, ${ }^{53}$ Floridablanca, de Perfecta Razón. ${ }^{54}$

Los artículos que aparecen en La Razón tendrán distinta procedencia. La mayoría van a pertenecer a la redacción de la revista, sin que

51 El enfrentamiento sería más duro entre La X y La Verdad, siendo el trato con La Razón más moderado. En La Razón podemos encontrar diversas poesías de Aurelia Mateo, así como su discurso de iniciación en la masonería y una prohibición a las esposas e hijas para leer $L a X$ y La Verdad.

52 La X, n 1 , de 9 de junio de 1889, pág. 1.

53 El mismo que fue director de El Clamor de Castellón, La Bandera Liberal y supuesto director de Cascarrita.

54 Centro Documental de la Memoria Histórica de Salamanca, legajo 752 A expediente 5, Carta del Venerable Maestro adjunto de Perfecta Razón al Vizconde de Ros explicando la situación de la logia por las acciones de José Baeza, con fecha de 23 de octubre de 1889. 
firme quien lo ha escrito. Otra fuente van a ser artículos escritos por masones de Castellón, tanto de la capital como de la provincia, firmándolos bien con el nombre simbólico, con las iniciales, sólo tres puntos, etc. También contará entre los colaboradores con librepensadores y liberales. El secretismo de la identidad por parte de los masones no va a permitir la mayoría de las veces descubrir de quién se trataba.

La logia Perfecta Razón se encargó al principio de su publicación y gestión, seguida por Castalia una vez abata columnas. Aparecen anuncios y resúmenes de algunas tenidas de instrucción, de las asambleas, tenidas fúnebres, así como otras actividades. No refleja en sus artículos sus opiniones o sus intereses particulares, sino que habla en términos de una masonería universal, dando así un sentido de unidad a toda la masonería de Castellón, y sin desprestigiar a ninguna de las obediencias existentes, más bien al contrario. El resto de las logias de Castellón también utilizarían la revista para anunciar sus actividades y relatar sus noticias, pero en una menor medida.

Defendía a la masonería como la que iba abrir los ojos a la luz de la verdad e invitaba a leer la revista para conocer los propósitos de la Institución. Se veían como tolerantes, defensores de la libertad y del progreso, renunciaban a ideas políticas y religiosas y trataban de unir a los hombres. La única convicción que debían tener los que pertenecían a la masonería era la creencia en el Gran Arquitecto del Universo, sin renunciar a ninguna religión.

La lucha contra el papel de la Iglesia en la sociedad castellonense será constante. Frente a la doctrina y el fanatismo, así como la fe ciega, anteponía la razón humana y lo que supone: las ciencias, las artes, la filosofía, es decir, la civilización en general. La Razón resistirá a los ataques procedentes de La Verdad y a la presión que va a ejercer sobre los masones, con continuas amenazas consistentes en revelar los nombres de los que componían la Orden y ofreciendo ventajas a quienes la abandonaran públicamente. En La Razón también vamos a encontrar duras palabras contra el principal redactor de La Verdad, Wenceslao Balaguer..$^{55}$ La lucha contra la Iglesia la realizaba también la masonería con la apertura de nuevos centros masónicos en la provincia. ${ }^{56}$

Desde la masonería se mostraban a favor de la labor realizada por el Casino de Artesanos de

55 Para que sirva de ejemplo, tenemos el artículo "Wenceslao Balaguer y el cura de Flix", en el que se narran actos de crueldad por parte del Vicario de la Iglesia de la Sangre y su participación en la última guerra carlista, en La Razón, núm. 14 de 21 de julio de 1889, pp. 2 y 3.

56 La Razón, núm. 9, de 16 de junio de 1889, p. 6. 
mejorar la educación y más concretamente de la Exposición sobre educación primaria elaborada por Germán Salinas, como luego veremos. La educación dispondría de amplio espacio en La Razón. Por supuesto, el sistema educativo que respaldaría iba a ser el impartido en escuelas laicas. A pesar de la relación del Casino de Artesanos con la masonería nunca comentaría nada al respecto.

Aunque difundía una imagen de la mujer más moderna que la de la Iglesia, entre las logias de la capital no vamos a encontrar a ninguna mujer iniciada en la masonería. Esta actitud la podemos ver reflejada en la única tenida de instrucción de Perfecta Razón publicada por la revista que trataba este tema, dándoles un papel relevante en la sociedad, pero una sociedad controlada por hombres, que veía a la mujer como a una compañera y a una inspiradora de éste. Eran capaces de reconocer todas sus bondades pero, aunque no lo dijeran expresamente, no veían que tuviera un lugar en una logia. ${ }^{57}$

Podemos leer en sus páginas la postura de las logias frente a las fiestas de julio, de cómo contribuyen al imaginario del Castellón liberal que luego aprovecharían los republicanos. ${ }^{58}$

Aparecen diversas poesías realizadas por masones de Castellón, con la temática del progreso, de los deberes de los obreros en las logias y por supuesto la religiosa.

Las dificultades para mantener económicamente la publicación se dieron desde el primer número. El Venerable Maestro, José Baeza Méndez, se apropió desde marzo hasta agosto de 1889 de buena cantidad del dinero de las suscripciones, dejando a La Razón en una situación delicada. ${ }^{59}$ El cobro de las suscripciones también sería un problema, sobre todo por parte de los suscriptores de fuera de la capital.

La Razón fue denunciada en varias ocasiones, siendo incluso encarcelado el director de la publicación por el delito de reproducir varios trabajos que han publicado otros periódicos sin ningún contratiempo. ${ }^{60}$ Estas denuncias, y sobre todo el juicio de Morayta, ${ }^{61}$ mermarían la situación económica de la lo-

57 "Influencia de la mujer en la familia y en la sociedad", tenida de instrucción de la logia Perfecta Razón de 1 de junio de 1889 por el Hermano Otumba, en La Razón, n 10, de 23 de junio de 1889, pp. 1 a 3

58 La Razón, n 12, de 7 de julio de 1889, p. 1.

59 Centro Documental de la Memoria Histórica de Salamanca, legajo 752 A expediente 5, Carta del Venerable Maestro adjunto de Perfecta Razón al Vizconde de Ros explicando la situación de la logia por las acciones de José Baeza, con fecha de 23 de octubre de 1889. 
gia que la sustentaba, que en estos momentos era Castalia. Debemos tener en cuenta que después del juicio de Morayta, en la sentencia no se consideraba motivo de delito atacar los actos de la asociación masónica por ser contrarios al dogma de la religión católica, ${ }^{62}$ por lo que La Verdad tenía campo libre para atacar a La Razón y a la masonería con total impunidad, y de seguro tenía la batalla ganada. Para acabar, Castalia no estaba pasando por buenos momentos, como se evidencia en que no se conservan Cuadros Lógicos de ese año y no hay ninguna reseña en el boletín de su oriente desde marzo de 1891.

La Razón nació, principalmente, por los continuos ataques de La Ver- dad a la masonería de la capital. Intentó dar una buena imagen de la Orden a una sociedad que se veía bombardeada con la desinformación que las publicaciones antimasónicas estaban difundiendo. Es cierto que los problemas de las logias que la sustentaban influyeron en el devenir de la publicación, pero la presión ejercida por los elementos religiosos hizo mella y fue decisiva para que la publicación finalizara.

\subsection{Casino de Artesanos}

La primera noticia sobre el Casino de Artesanos apareció en El Clamor de la Democracia el 22 de enero de $1882,{ }^{63}$ reseñando que se

60 La Razón, núm. 30, de 10 de noviembre de 1889, p. 3.

61 El presbítero Wenceslao Balaguer y el reverendo de Tortosa, Andrés Serrano García-Vao, fueron denunciados por Miguel Morayta, en representación de la masonería española, por supuestas injurias y calumnias a la Orden en verano de 1889. El juicio oral se llevó a cabo en noviembre de 1890 en Castellón. En la sentencia, se absolvía a los denunciados porque la sociedad masónica que la denunciaba no existía como tal en el momento de la denuncia y no se consideró que hubiera delito. Se puede consultar mi trabajo de investigación antes mencionado, pp. 151 a 156 principalmente, para profundizar sobre el tema y considerar con mayor profundidad las consecuencias que tendría sobre la masonería.

62 Según sentencia del Tribunal Supremo de 21 de noviembre de 1888. La Razón, n 83, 16 de noviembre de 1890, p. 5.

63 Ferrán Archilés asegura que fue fundada en 1879 y que perduró a lo largo de los años veinte, aunque como podemos comprobar en El Clamor de la Democracia, esta institución data de 1882. Archilés también lo señala como un centro de la Masonería castellonense; sin embargo, no lo fue durante toda su existencia, como veremos. Por último, muestra la relación entre el republicanismo y el Casino, teniendo que matizar que hasta al menos no entrada la década de los noventa no vemos esta relación. Ferrán Archilés Cardona, Parlar en nom del poble. Cultura política, discurs i mobilització social al republicanisme castellonenc (1891-1909), en Castelló d'Impressió, S.L., 2002, p. 66. 
había presentado a la aprobación del señor gobernador el reglamento de esta nueva sociedad. ${ }^{64}$ El 29 de enero ya contaba con ciento ochenta socios. Las reuniones las realizaba en lo que fue el Casino Castellonense. ${ }^{65} \mathrm{El}$ domingo 12 de febrero se produjo la inauguración. ${ }^{66}$

Esta sociedad no fue formada bajo iniciativa masona, y su incursión se fue produciendo poco a poco. Al tratarse de una sociedad de recreo era normal la realización de bailes de confianza y conciertos. Además, incluía la realización de conferencias con la finalidad de instruir a sus socios. En estas conferencias iba a ser normal la participación de conferenciantes que pertenecieran a la masonería. Por ejemplo, la velada lírico-literaria del 6 de diciembre de 1885 contó con la participación de José Fola Igurbide, Victoriano Montés, Bernardino Montiel, Germán Salinas y Fernando Gasset, que en esos momentos ya eran masones ${ }^{67} y$ buscaban expandir la orden desde la logia Tres Estrellas. Otro ejemplo es la conferencia a cargo de Fernando Gasset el sábado 29 de mayo de 1886 , sobre "La vida obrera en las ciudades". 68

\section{Exposición de Castellón de 1887}

Una vez Tres Estrellas hubo formado Progreso y Esperanza $V$ se dedicaron a buscar la forma de expandir la Orden, tanto por la capital como por la provincia. La junta directiva del Casino de Artesanos de 1887, a excepción de dos vocales, estaba formada por masones en activo de las logias antes mencionadas. ${ }^{69}$ Nos permite hacernos una idea del control que tenían.

Después de disponer de una presencia activa en el Casino de Artesanos, la celebración de una exposición local, como había sido la de Zaragoza de $1885,{ }^{70}$ era una buena iniciativa para desarrollar sus

64 El Clamor de la Democracia, núm. 8, de 22 de enero de 1882, pág. 3.

$65 \mathrm{El}$ hecho de que contara con tantos socios al inicio presupone que debían provenir de alguna sociedad anterior. El Clamor de la Democracia, núm. 10, de 29 de enero de 1882, p. 3.

66 A partir de la inauguración, aparecerán reseñados en esta publicación varios bailes. El Clamor de la Democracia, núm. 15, de 16 de febrero de 1882, p. 3.

67 El Clamor de Castellón, núm. 55, de 10 de diciembre de 1885, p. 3.

68 El Clamor de Castellón, núm. 104, de 3 de junio de 1886, p. 2.

69 El Clamor de Castellón, núm. 269, de 5 de enero de 1888, p. 2.

70 Encontramos un suelto referente a esta exposición en El Clamor de Castellón, n 339, de 2 de abril de 1885 , p. 3 . El planteamiento que adoptará la de Castellón será la de ésta de Zaragoza, con distintas secciones y la realización de un concurso. Recordemos también que estaba muy próxima la Exposición de París de 1889. 
fines. Aprovecharían, además, las fiestas de julio, seguramente para conseguir una mayor afluencia.

El 20 de febrero de 1887 se celebró la primera reunión en el Casino de Artesanos para organizar la exposición de julio ${ }^{71}$ y se formaron diversas comisiones: de agricultura, industria y comercio y artes.

Éste era el espíritu que el Casino de Artesanos quería imprimir a este evento, tal y como aparece en $E l$ Clamor de Castellón

Nuestra época se distingue por un espíritu de universalidad esencialmente práctico y tiende a hermanar lo bello y lo útil; este carácter deben revestir los certámenes.

No sólo el poeta, sino el industrial, el comerciante y el agricultor deben interesarse en tales fiestas.

No sólo el talento, el ingenio y el trabajo deben obtener premio y recompensa a sus esfuerzos, sino la virtud y la desgracia deben obtener también su galardón.

\section{Para ello su deseo sería}

Alentar la virtud, favorecer la industria, la agricultura, las artes y el comercio y fomentar la instrucción, deberes son de las corporaciones populares, e indudablemente ningún medio más práctico y fácil de realizar tales deberes es el de promover certámenes y exposiciones. ${ }^{72}$

Uno de los propósitos de la masonería de Castellón referente a este evento era difundir la Orden, así que después del artículo en El Clamor apareció el Código Masónico.

Otro de los propósitos de la Exposición era unir a los pueblos del Maestrazgo y de la Plana, divididos desde la guerra, congregándose bajo una mira común para rendir culto y vasallaje al rey de todos. Al trabajo. $^{73}$

Se llevaría a cabo en el gran patio del Instituto de Segunda Enseñanza, en el que se realizaron las obras estructurales necesarias, cubierto por un gran toldo e iluminado por electricidad. ${ }^{74}$

71 El Clamor de Castellón, núm. 179, de 24 de febrero de 1887, p. 2.

72 El Clamor de Castellón, núm. 192, de 10 de abril de 1887, p. 2.

73 El Clamor de Castellón, núm. 201, de 12 de mayo de 1887, p. 2.

74 Recordemos que en aquellos años el alumbrado público era de gas hidrógeno. 
Se celebró durante la Exposición una rifa con objetos donados por los vecinos de la ciudad a favor de los pobres, organizada por la junta de gobierno del Casino de Artesanos. El total de objetos pasaba los 1.800 a la hora de cerrar el número de $E I$ Clamor de Castellón de 3 de julio de 1887, montando dos pabellones para la rifa, uno en el patio del instituto y otro en el parque Ribalta. ${ }^{75}$

Las revistas de Barcelona y de otros centros se ocuparon de la Exposición, dando idea de la repercusión que iba tomando antes de abrir sus puertas. Son muchas las expectativas que se iban generando sobre ella. ${ }^{76}$

La apertura de la exposición tuvo lugar el 3 de julio a las 10 de la mañana en el Instituto de Segunda Enseñanza. ${ }^{77}$ La Exposición se esperaba que estuviera abierta hasta el día 25 de julio. ${ }^{78}$ Sin embargo, cerró sus puertas definitivamente el 20 de julio, siendo los dos últimos días de entrada libre. Lo único que quedaba ya era que el jurado resolviera el reparto de los premios. En El Clamor de Castellón de 31 de julio apareció publicada la larga de lista de los premios de la Exposición. ${ }^{79}$ Finalmente, el domingo 16 de octubre tuvo lugar la entrega de premios en el Teatro Nuevo. ${ }^{80}$

Las logias que participaron en la realización de este Exposición fueron Tres Estrellas, Progreso y Esperanza $V$, y por supuesto el Capítulo Tres Estrellas, ${ }^{\circ} 28.81$ En todo momento fue vista con agrado la realización de esta exposición por parte del gran oriente bajo el que estaban auspiciadas. Así podemos comprobarlo en una comunicación durante los días de la exposición

Logia Esperanza 5a, núm. 214. Entusiasta comunicación anunciando haberse celebrado el banquete solsticial con la asistencia absoluta de todos

75 El Clamor de Castellón, núm. 216, de 3 de julio de 1887, p. 2.

76 El Clamor de Castellón, núm. 211 , de 16 de junio de 1887, pp. 2 y 3.

77 Ver sobre la inauguración y marcha de la exposición en Juan A. Balbás, El libro de la provincia de Castellón, Editorial Confederación Española de Cajas de Ahorros, Castellón, 1987.

78 El Clamor de Castellón, núm. 220, de 17 de julio de 1887, p. 2.

79 El Clamor de Castellón, núm. 224, de 31 de julio de 1887, p. 3. Sólo unos pocos masones fueron premiados.

80 El Clamor de Castellón, núm. 245, de 13 de octubre de 1887, p. 2.

81 Del Gran Oriente de España estaba posiblemente en activo la logia Verdad, pero no hay documentación desde 1884. Es imposible saber si algún masón de esta logia que no se encontrara en el Cuadro Lógico de 1883 hubiera podido intervenir. 
los $\mathrm{HH}$., quienes acogieron con alegría las comunicaciones del Grande Oriente, referentes a la Exposición de aquellos Valles y demás asuntos de la Orden; progresos que el Capítulo y las tres Logias realizan, y gratas esperanzas para el porvenir.

El Grande Oriente quedó satisfechamente enterado, reiterando su acuerdo de cooperar a la noble empresa en que se hallan empeñados. ${ }^{82}$

El resultado fue muy positivo para los masones que intervinieron en la exposición, ya que se vieron recompensados por su oriente en forma de ascensos de grados. ${ }^{83}$

Después de un año, todavía se recordaba la exposición en las comunicaciones con el oriente, admirando la buena relación y el buen trabajo de las logias de la provincia

No menos expresiva y entusiasta fue la acogida que en Castellón obtuvo nuestro Gran Secretario de aquel Capítulo Provincial, y de la Logia Tres Es- trellas núm. 135, Progreso núm. 213 y Esperanza V núm. 214, y representación de la Verdadera Luz de Segorbe, donde pudo admirar el buen estado de los Talleres, que es necesario ver de cerca para comprender su vasta importancia, la íntima afinidad y noción de miras que a sus $H H$. . distingue, y de la que brotó un día la Exposición del Trabajo que realizaron el año pasado con plácemes de propios y extraños, abriendo público palenque en que demostrar sus talentos al industrial, al obrero y al artista, y de la que brotarán a no dudarlo nuevos gérmenes de luz y de progreso, pues latente está la actividad de todos ellos y vivo y en auge el Centro de Instrucción ${ }^{84}$ por ellos fundado y a que todos concurren ${ }^{85}$

82 Boletín Oficial del Serenísimo Grande Oriente Nacional de España, núm. 1, de 15 de julio de 1887 , p. 2.

83 Boletín Oficial del Serenísimo Grande Oriente Nacional de España, núm. 12, de 30 de diciembre de 1887, p. 4.

84 Se podría referir al Casino de Artesanos y a sus conferencias, aunque sabemos que no fue fundado por ellos.

85 Boletín Oficial del Serenísimo Grande Oriente Nacional de España, núm. 29, de 15 de septiembre de 1888, p. 7. 
de los objetivos de la Exposición se había cumplido.

Sirvió de escaparate para manifestaciones artísticas, industriales y comerciales, así que este objetivo también se cumplió, y además de forma muy satisfactoria, dada la cantidad de gente que participó y asistió al evento.

Sin embargo, no todo pudieron ser buenas críticas. A pesar de que La Verdad no existía en el momento de la Exposición, ${ }^{86}$ más tarde dio su punto de vista sobre este evento a propósito de hablar de la caridad masónica. Tenía clara la intervención de la masonería en la Exposición

Todos sabemos que la masonería anduvo de por medio hasta el punto que en la Exposición se vio que recaudaban y mangoneaban algunos que el público señala como masones...

Pues bien, aquella Exposición se inició en el Casino de Artesanos, y allí se nombraron las juntas, entre cuyos individuos había bastantes masones.

Además, La Verdad tenía su versión de la evolución del Casino de
Artesanos y de cómo la masonería se introdujo en esta sociedad

Aunque el Casino de Artesanos fue en su fundación un local de esparcimiento e instrucción para los jóvenes, hoy no es lo mismo. Desde aquella junta en que fueron derrotados dos artesanos tan honrados como $D$. Fermín Andreu, Presidente del Casino, y D. Joaquín Moliner, Vocal de la Junta, por querer despedir de la Sociedad a un secretario de una Logia masónica, se manifestaron los trabajos de zapa de la masonería, y la influencia que allí tiene. ${ }^{87}$

\section{La exposición sobre ins- trucción primaria}

Las actividades del Casino de Artesanos del año 1888 comenzarían con conferencias de Fernando Gasset y Enrique Perales, y serían criticadas por elementos católicos, pero no por masonas, sino por ser de carácter liberal. Baste de ejemplo las palabras del señor Dios Rubio durante la misa del primero de año provocando el enfado de la redacción del El Clamor de Castellón. ${ }^{88} \mathrm{El}$ aumento de las reseñas

86 Comenzó a publicarse el 9 de diciembre de 1888.

87 La Verdad, $\mathrm{n}^{\circ} 5$, de 6 de enero de 1889, p. 2.

88 Ibíd., pág. 2. 
de las conferencias en la publicación demuestra la relevancia que van adquiriendo. Conferencias que tenían una periodicidad semanal y con bastante afluencia de público, por tanto podemos pensar en su importancia como elemento difusor del mensaje de la masonería.

Pedro Aliaga realizó en el Casino de Artesanos una conferencia el 10 de diciembre sobre el tema "Higiene de Castellón". La junta de la sociedad, tras esta conferencia, se hizo eco de las carencias que presentaban los centros educativos y se puso en marcha para solucionarlos. La reunión del 22 de diciembre de 1888 impulsada por el Casino de Artesanos con la finalidad de mejorar la instrucción primaria de la localidad resultó ser bastante concurrida. Se reunieron personalidades de Castellón distinguidas en ciencias, artes o industria y después de tratar el tema se tomó la determinación de nombrar una junta gestora para presentar un proyecto de escuelas y cualquier otra proposición sobre el tema de la reunión. De esta junta sólo podemos destacar como masones a Fernando Gasset y al Presidente del Casino de Artesanos,
Gaspar García. ${ }^{89}$ Mientras tanto, con la renovación de la junta del Casino de Artesanos para 1889 se seguía manteniendo la presencia masónica en esta institución, ocupando casi todos los cargos. ${ }^{90}$

El 7 de enero de 1889 se volvió a reunir la junta gestora creada para tratar el tema de la instrucción primaria, después de una conferencia de Fernando Gasset bajo el tema "Exposición de diversos sistemas y procedimientos de presentación político-social". El presidente de la junta pasó a explicar los resultados, dando a conocer que el señor Salinas tenía redactada una solicitud al ayuntamiento para pedir la construcción de escuelas, leyendo éste el trabajo realizado.91

La Verdad va a criticar la apertura de escuelas laicas que se pretendían llevar a cabo con la Exposición del señor Salinas. Veía en esta cuestión la pretensión de apoderarse de la juventud por medio de ellas, y la revista no lo iba a permitir. ${ }^{92}$ Por supuesto, la mano de la masonería estaba detrás de esto, y las órdenes venían dadas desde el centro de la masonería, el Gran Oriente de España. ${ }^{93}$

89 El Clamor de Castellón, núm. 377, de 27 de diciembre de 1888, p. 1.

90 El Clamor de Castellón, núm. 380, de 6 de enero de 1889, p. 2.

91 El Clamor de Castellón, núm. 381, de 10 de enero de 1889, pp. 2 y 3.

92 La Verdad, n $^{\circ} 5$, de 6 de enero de 1889, pp. 1 y 2.

93 Debemos tener en cuenta que desde La Verdad se piensa en una masonería española unida bajo un mismo oriente; como sabemos no es así. También lo llamaba en el mismo artículo el Gran Oriente de la Masonería Española 
A pesar de realizar trabajos que sin duda estaban inspirados por el espíritu de la masonería, ante cualquier insinuación de ese tipo se desmentía inmediatamente. Así ocurría en una carta que dirigía el Presidente del Casino de Artesanos, y masón, Isidro Ribas al director de El Clamor para desmentir unas insinuaciones aparecidas en el número 96 de La Provincia referentes a la relación de esta sociedad con la masonería. Era común entre los masones castellonenses negar la pertenencia a este tipo de sociedades, y este es un buen ejemplo.

El Casino de Artesanos ha auxiliado como otras sociedades recreativas a los pobres jornaleros ${ }^{94}$ en los pasados días, sin que estos socorros tengan nada de común con los que la masonería haya podido hacer.

Ignoro las ideas y tendencias de los socios de este Casino, al que inútilmente tratará de tildarse, pues que no se ha de separar ni una sola línea de las disposiciones contenidas en su reglamento, que prohibe en ab- soluto toda clase de cuestiones políticas y religiosas. ${ }^{95}$

Las afirmaciones que aparecieron en La Provincia fueron extraídas de La Verdad. En su artículo "En la brecha" no duda de su relación con la masonería. ${ }^{96}$ No sólo estaba en contra de este Casino por ser un nido de masones, sino que también estaba en contra, por supuesto, de la implantación de escuelas laicas en la capital.

Estos ataques tendrán sus efectos, y en la siguiente conferencia del Casino de Artesanos sólo encontraremos en El Clamor un escueto anuncio con el día en que se realizó, nombre del conferenciante, Anselmo Jordán, y el tema, "La situación de la clase obrera. Necesidad de su mejoramiento. Indicación de alguno de los medios para conseguirlo". 97 En el siguiente número de la publicación no encontramos reseña explicando cómo fue la conferencia.

La Verdad va a dedicar duras acusaciones al Casino de Artesanos

94 En este punto la carta de Isidro Ribas tiene razón, ya que se abrieron suscripciones en el Casino Antiguo, de Artesanos y de Labradores para remediar las necesidades de la clase obrera. El Clamor de Castellón, núm. 381, de 10 de enero de 1887, p. 2.

95 El Clamor de Castellón, núm. 383, de 17 de enero de 1889, p. 3.

96 La Verdad, núm. 6, de 13 de enero de 1889, pp. 1 y 2.

97 El Clamor de Castellón, núm. 386, de 27 de enero de 1889, p. 2. 
A los cargos que hemos hecho al Casino de Artesanos, señalándolo como centro enemigo de la Religión, anticatólico, impío y masón, responden los hh. . con la conspiración del silencio...

Sabido es que la sala de davant del Casino es la elegida para reunirse los masones, y al instante que entra un profano se esparcen por las salas para llevar a término su propaganda impía...

En público niegan su filiación masónica...

¿Quién se atreve a llevar aquí el sambenito de masón? Nadie. $^{98}$

El Clamor apoyaría la labor realizada por el Casino por la instrucción primaria y publicó un artículo de primera página titulado "Vuelta a la brecha", en clara alusión al artículo antes mencionado de La Ver- dad. En él, explicaría la situación de la educación en Castellón. ${ }^{99}$

Mientras tanto, la exposición de Salinas seguía su curso. El 1 de febrero hubo una reunión en el Casino de Artesanos a la que asistieron, previa convocatoria, ex diputados y ex senadores a cortes, diputados provinciales, concejales, catedráticos, ingenieros, representantes de la prensa y todo lo más notable de esta ciudad. ${ }^{100} \mathrm{El}$ clero no asistió, a pesar de estar convocado. ${ }^{101}$

Se aprobó y firmó la exposición sobre instrucción primaria. El siguiente paso fue la recogida de firmas, acudiendo a todos los Casinos y sociedades de Castellón ${ }^{102}$ y finalmente el 20 de febrero se entregó la instancia sobre reformas de instrucción primaria en el ayuntamiento, respaldada por más de mil firmas. ${ }^{103}$ Ante esta recogida de firmas, la revista antimasónica reaccionó de la siguiente forma

98 La Verdad, núm. 8, de 27 de enero de 1889, p. 3.

99 El Clamor de Castellón, núm. 388, de 2 de febrero de 1889, p. 1.

100 lbíd., p. 3.

101 Aquí dio sus razones, La Verdad, n 8 de 27 de enero de 1889, p. 4.

102 El Clamor de Castellón, núm. 390, de 10 de febrero de 1889, p. 3.

103 Es importante el número de firmas, ya que sólo firmaron los que sabían leer y escribir, cifra que no era muy superior al número de firmas recogidas. El Clamor de Castellón, núm. 394, de 24 de febrero de 1889, pg. 2. 
Estos haches no dan pie con bola: ahora van por esa ciudad mendigando firmas para dirigir una exposición al Ayuntamiento, y como por todas partes se meten, aunque no les llamen, un día se presentaron a un católico que leyó la exposición y dijo al demandante:

-Tome V. ese papel y vaya con Dios, que yo no firmo exposiciones redactadas por el $H . \cdot$ Salinas y autorizadas por el H. . Ribas y el H. . Sos.

Así, así proceden los buenos católicos. ${ }^{104}$

La Verdad no se detendrá en su empeño en impedir que siga adelante el proyecto. ${ }^{105}$ Ve en la exposición la manera de reactivar esta asociación, que desde la exposición de 1887 no había hecho nada significativo. ${ }^{106} \mathrm{El} 16$ de febrero se produjo un suceso inusual, la po- licial registró los locales de varios casinos de la capital. No sabría decir hasta qué punto la presión de ciertos elementos católicos sobre el poder civil podría haber estado detrás de este suceso.

La revista masónica La Razón, en su primer número, apoyaba la labor que estaba realizando el Casino de Artesanos a favor de la instrucción primaria y la defendía de los ataques. ${ }^{107} \mathrm{El}$ Clamor también defendió el proyecto emprendido por esta sociedad. ${ }^{108}$

La exposición sobre instrucción primaria fue frenada, y después de dos meses de su presentación no había comenzado a producir resultados. Desde el ayuntamiento se formó una comisión con la finalidad de tratar el asunto, pero a finales de abril aún no se había reunido, cuestionándose desde El Clamor la influencia de La Verdad en este asunto. ${ }^{109}$

104 La Verdad, n 11 de 17 de febrero de 1889, p. 6.

105 La Verdad va a dedicar cinco extensos artículo a combatir esta exposición titulados “¡Al lobo!

¡Al lobo!", relacionando al Casino de Artesanos y la exposición a la masonería, mostrando las intenciones poco claras de esta asociación supuestamente recreativa.

106 La Verdad, $n^{\circ} 12$, de 24 de febrero de 1889, p. 2.

107 La Razón, núm. 1, de 1 de marzo de 1889, p. 6.

108 El Clamor de Castellón, núm. 398, de 10 de marzo de 1889, p. 2.

109 El Clamor de Castellón, núm. 408, de 14 de abril de 1889, p. 2. 
El trabajo realizado a lo largo del tiempo por el Casino de Artesanos va a dar sus frutos, $y$ en estos momentos aumentaba el número de socios en detrimento del Nuevo Casino, ${ }^{110}$ a pesar de los ataques recibidos desde otras publicaciones, saliendo reforzado. ${ }^{111}$ La Verdad apreciaba de diferente manera la evolución que había tenido, ${ }^{112}$ y el efecto de su sección "A la picota" no sólo se notaría en el número de bajas en el Casino, sino en el efecto sobre los que allí acudían, fueran o no masones. ${ }^{113}$

Desde La Razón se defendía al Casino de Artesanos y se daban cifras del aumento en el número de sus socios

La diatriba constante de La Verdad contra el Casino de Artesanos va produciendo excelente efecto.

En menos de dos meses se han inscrito más de sesenta socios, siendo el número total de estos 500.
Continúe, pues, La Verdad en su tarea, seguro que se lo agradecerán mucho los que tienen más interés en la existencia y prosperidad de dicho centro de instrucción y recreo. ${ }^{114}$

El Casino de Artesanos organizó veladas teatrales en el Teatro Nuevo desde octubre de 1889, con temática republicana y liberal, como por ejemplo la zarzuela El gorro frigio, ${ }^{115}$ prolongándose hasta fin de año, momento en que se reanudaron las conferencias semanales en su local. También tuvo La Verdad palabras de desapruebo para estas representaciones. ${ }^{116}$

Después de más de un año de ser presentada la exposición sobre instrucción primaria la cuestión fue olvidada por el ayuntamiento, aunque con el cambio de gobierno se albergaban esperanzas de que se retomara. ${ }^{117}$

110 El Clamor de Castellón, núm. 401, de 21 de marzo de 1889, p. 2.

111 El Clamor de Castellón, núm. 423, de 6 de junio de 1889, p. 2.

112 La Verdad, núm. 15, de 17 de marzo de 1889, p. 7.

113 La Verdad, núm. 18, de 7 de abril de 1889, p. 7.

114 La Razón, núm. 24, de 29 de septiembre de 1889, p. 6.

115 El Clamor de Castellón, núm. 458, de 10 de octubre de 1889, p. 2.

116 La Verdad, núm. 48, de 3 de noviembre de 1889, p. 6.

117 El Clamor de Castellón, núm. 530, de 22 de junio de 1890, pp. 1 y 2. 


\section{La crisis de la masonería} en Castellón y el Casino de Artesanos

Podemos ver la repercusión de la crisis de la masonería de Castellón en la elección de la junta directiva de este círculo en enero de 1891, 118 con los siguientes cargos ocupados por masones: presidente, vicepresidente, tesorero, contador, vicesecretario, y dos vocales. ${ }^{119}$ También va a suponer la pérdida de peso en la sociedad castellonense, realizando como más destacado bailes y conferencias, así como la participación en celebraciones típicas del Castellón de la época, como la manifestación cívica de las fiestas de julio.

Después de la conferencia de 23 de marzo de 1891 en el Casino de Artesanos por Fernando Gasset acerca del gobierno de los pueblos, éste indicó la conveniencia de llevar a cabo una cátedra para dar cursos de 15 o 20 lecciones sobre los temas que más interesen a la clase obrera, para hacer más prácticas las conferencias. ${ }^{20}$
Antes de la elección de la siguiente junta representativa sucedió un hecho que sólo aparece reflejado en La Hoja Suelta. Por lo visto, y según cuenta, a consecuencia de las reuniones masónicas que se celebraban en un salón del local hubo alguna queja por parte de dos socios. Tras la reunión de la junta, estos dos señores fueron expulsados por un acto de desobediencia, acudiendo ante la primera autoridad de la provincia con la intención de revelar muchas cosas en contra de dicha sociedad. La publicación no conocía el nombre de los denunciantes, pero aplaudía su actitud de lucha contra los que trataban de imponerse, la mayoría de veces, por el procedimiento del terror. ${ }^{121}$

En la siguiente elección de junta representativa del Casino para 1892 se sigue notando que la Orden no está pasando por sus mejores momentos, aún así aguantaría en cuanto a la representatividad dentro de esta sociedad: presidente, vicepresidente, tesorero, contador, bibliotecario y dos vocales. ${ }^{122}$

118 Por estas fechas se dejaba de publicar la revista masónica La Razón. El último número publicado fue el del 4 de enero de 1891.

119 El Clamor de Castellón, núm. 586, de 4 de enero de 1891, p. 2.

120 El Clamor de Castellón, núm. 609, de 26 de marzo de 1891, p. 2.

121 La Hoja Suelta, $n^{\circ} 16$, de 13 de diciembre de 1891, p. 2.

122 El Clamor de Castellón, núm. 691, de 6 de enero de 1892, p. 3. 
El Casino de Artesanos tuvo una discreta participación en la iniciativa para la construcción de un Obelisco en conmemoración de los acontecimientos de julio de 1837. Participó en los actos realizados para la construcción del Obelisco, pero no de forma tan destacada como lo hubiera hecho seguramente en épocas anteriores.

En la elección de la junta representativa para 1893 encontramos sólo a tres masones, o socios que habían pertenecido a la masonería: ${ }^{123}$ presidente, contador y vice-secretario. ${ }^{124} 1893$ será un año complicado para esta sociedad, pasará por un proceso de inactividad y casi no se van a dar conferencias. ${ }^{125}$

La junta representativa para 1894 tampoco va a tener casi presencia masónica: presidente, vicepresidente y un vocal. ${ }^{126}$ Por parte de su nuevo presidente se van a retomar las conferencias, pero el peso de este Casino no va a ser el mismo.
Teniendo en cuenta el desarrollo de las logias masónicas en Castellón podemos plantearnos la naturaleza de las acciones que se desarrollen. Durante el año anterior no hubo actividad de las logias del Gran Oriente Nacional de España y es a finales de 1893 cuando se reconstruye la logia El Progreso, por lo que surge la duda de si considerar masones o no a los que en un momento formaron parte de la Orden y se encontraban en ese momento en la junta del Casino. Al desaparecer la infraestructura masónica que tanto había conseguido en el pasado, considero que la masonería ha perdido la influencia que tenía y por tanto las acciones que realice a partir de 1893 no van a ser impulsadas por una masonería organizada de Castellón.

En la Junta representativa 1895 tenemos como masones al presidente, al tesorero y un vocal. ${ }^{127}$

Aparecía un anuncio del Casino de Artesanos el 25 de julio de 1895

123 Simplemente recordar que en 1893 no había ninguna logia en funcionamiento y que el último Cuadro no iba más allá de 1889.

124 El Clamor de Castellón, núm. 796, de 12 de enero de 1893, p. 2.

125 El Clamor de Castellón, núm. 903, de 25 de enero de 1894.

126 Ninguno de ellos va a aparecer en el Cuadro Lógico de Capítulo Integridad o de Progreso de 1895 y sólo Vicente Sos aparece en el Cuadro Lógico de Capítulo Integridad de 1889, último hasta el de 1895.

127 El Clamor de Castellón, núm. 1000, de 3 de enero de 1895, p. 2. 
sobre un acuerdo de la junta representativa del 21 , en la que tomaba medidas para intentar aumentar el número de socios. ${ }^{128}$ Pero en ese momento, por lo visto, los pocos masones de Castellón ya no podían contar con esta sociedad.

\subsection{Conclusiones}

A lo largo de este artículo hemos estado comprobando de qué forma la masonería fue introduciéndose en la sociedad castellonense de la Restauración. Los nuevos planteamientos sociales que representaba debieron atraer a los elementos progresistas de la burguesía, deseosa de un cambio de la situación, que resultaba inviable tras la instauración del sistema turnista. La logia les permitía recrear una situación de igualdad y de libertad de conciencia que tardaría bastante tiempo en materializarse.

La masonería estuvo en contacto con la sociedad con la que convivió $y$, de alguna forma, intentó cambiarla en el momento en el que contó con una importante infraestructura de logias y transmitió sus planteamientos a la sociedad castellonense de su época por diversas vías. Por un lado, buscaron la expansión de la Orden, y lo consiguieron de forma satisfactoria durante un periodo que iría de mediados a finales de la década de 1880. Por otro lado, controlaron parte de la red social de la ciudad con el control del Casino de Artesanos, realizando campañas en pro de la difusión cultural, de la ayuda social y del crecimiento y expansión económica.

Pero estas intenciones se encontraron con la oposición de los que venían disfrutado del monopolio en ciertas actividades, como es el caso de la educación primaria. La Iglesia y los conservadores iban a ser los elementos a combatir. Comenzaron a aparecer publicaciones católicas destinadas a atacar a la burguesía que iba incorporándose a las filas republicanas y que, en ese momento, se encontraba militando en la masonería.

La Razón sirvió como primera barrera de contención contra los ataques que La Verdad estuvo realizando sobre la Orden en la capital. Pero la masonería no sólo se dedicó a defenderse. Estuvo influyendo en la sociedad castellonense mediante la participación, principalmente, en el Casino de Artesanos, y apoyó 
al republicanismo de la capital. ${ }^{129}$ En primer lugar, porque los masones más importantes pertenecían a esta corriente política, $y$, en segundo lugar, porque se dio cuenta de que si quería que sus propuestas se llevaran adelante debía conseguir influencia en el consistorio, como pudimos comprobar en el caso de la Exposición de Salinas.

Queda por plantear los causas de la crisis de la masonería a principios de la década de 1890. La presión del elemento religioso pudo tener cierto peso en que esto sucediera. Debemos tener en cuenta la actuación de los elementos antimasónicos y darles protagonismo. En 1889 la situación comenzó a ser crítica, y como hemos visto, en 1891 la masonería se encontraba muy reducida en la capital. ¿̇Obra de La Verdad?, posiblemente. ${ }^{130}$ Fueron adjurando públicamente masones importantes como Eduardo Portalés - Enrique Perales; Fernando Gasset llegó a adjurar, pero no de la forma que le hubiera gustado a La Verdad. ¿Pudo el miedo a ser señalados como masones razón suficiente para dejar la masonería? Seguramente lo sería en bastantes casos.
Otra razón sería la apertura de nuevas vías de participación en la sociedad castellonense para la mediana burguesía de finales del XIX, que haría perder atractivo a las logias.

Por último, la crisis de los orientes a los que estaban auspiciados las logias de Castellón tuvo como resultado la desaparición definitiva de la masonería en Castellón, al menos en lo que respecta al siglo XIX.

129 Se puede ampliar la relación entre masonería y republicanismo en mi trabajo de investigación antes mencionado.

130 Después del juicio de Morayta, esta publicación afirmaba que se produjeron multitud de bajas en las logias. La sentencia suponía vía libre por parte de La Verdad para realizar afirmaciones en contra de la masonería, como hizo en los números inmediatos a la realización del juicio. 


\section{FUENTES Y BIBLIOGRAFÍA}

\section{Fuentes}

Centro Documental de la Memoria Histórica de Salamanca - Sección Masonería: Boletines oficiales de diversos grandes orientes y libros de actas. Expedientes de las logias de Castellón y fichas policiales.

Archivo Municipal de Castellón: Publicaciones de Castellón, entre las que destacan El Clamor de Castellón, El Clamor de la Democracia, La Razón y La Verdad.

\section{Bibliografía}

Artículos

ALESSANDRO MOLA, Aldo: "El problema del anticlericalismo y la masonería". En José A. Ferrer Benimelli (coord.), Masonería y religión: convergencias, oposición, íncompatibilidad? Editorial Complutense, Madrid, 1996., pp. 239-251.

ARCHILÉS, Ferrán: "Una nacionalización no tan débil: patriotismo local y republicanismo en Castellón (1891-1910)". Ayer, n ${ }^{\circ}$ 48. Madrid, 2002. Pp. 283-314.

BEAUREPAIRE, Pierre Yves: "Sortir de L'impasse "maçonnologique": les sources d'une historie interculturelle de la franc-maçonnerie europeene". En Christine GAUDIN y Eric SAUNIER (coord.), Fran-maçonnerie et histoire. Bilan et perspectives, Publications des Universités de Roven et du Haure, Roven, 2003, pp. 53-74. BRINES BLASCO, Juan: "Masonería y política en el País Valenciano". En
José A. FERRER BENIMELI (coord.), La Masonería en la España del siglo $X X$. Universidad de Castilla La Mancha, Toledo, 1996, pp. 137-152.

CRUZ OROZCO, José Ignacio: "Laicismo escolar, anticlericalismo y masonería en la España contemporánea. Datos para una reflexión". En José A. FERRER BENIMELLI (coord.), Masonería y religión: convergencias, oposición, ¿incompatibilidad? Editorial Complutense, Madrid, 1996., pp. 253-269.

ESCALERA, Javier: "Asociacionismo y antropología". En Elena MAZA ZORRILLA (coord.), Asociacionismo en la España contemporánea. Vertientes y análisis interdisciplinar, Instituto Universitario de Historia Simancas, Valladolid, 2003, pp. 9-20. ESCUDERO, José Antonio: "Las sociedades secretas ante la legislación del siglo XIX". En José A. FERRER BENIMELI (coord.), Masonería Política y Sociedad, Centro de Estudios de la Masonería española, Zaragoza, 1989, pp. 511-544.

FERRER BENIMELI, José Antonio: "El Gran Oriente Lusitano Unido y los masones españoles (18691878)". En José A. FERRER BENIMELI (coord.), "La masonería en la España del siglo XIX", Valladolid, Junta de Castilla y León, Valladolid, 1987, pp. 497-528.

FERRER BENIMELI, José A.: "La Iglesia católica y la masonería: visión histórica". En José A. FERRER BENIMELI (coord.), Masonería y religión: convergencias, oposición, i̇incom- 
patibilidad? Editorial Complutense, Madrid, 1996, pp. 187-201.

FERRER BENIMELI, José A.: "Métodos y experiencias en el estudio de la historia de la masonería española", Revista de Estudios Históricos de la Masonería Latinoamericana y Caribeña, vol. 1, núm. 2, (Diciembre 2009-abril 2010), Universidad de Costa Rica, pp. 49-50.

MARTíN MARTíNEZ, Luis P.: "La Masonería, un ejemplo de historia Cultural. Reflexiones conceptuales y de método". En José A. FERRER BENIMELI (coord.), La masonería española en el 2000. Una revisión histórica, Gobierno de Aragón, Zaragoza, 2001, pp. 1027-1048.

RANDOUYER, Françoise: "Logia Amor. Un prototipo de la masonería madrileña". En José A. FERRER BENIMELI (coord.), La Masonería en Madrid y en España del siglo XVIII al XXI, Gobierno de Aragón, Zaragoza, 2004, pp. 3-35.

RODRÍGUEZ MARTíNEZ, Eugenia: "Masonería e Iglesia en Castilla-La Mancha". En José A. FERRER BENIMELI (coord.), Masonería, política y sociedad, Centro de Estudios de la Masonería Española, Zaragoza, 1989, pp. 773-782.

ROLDÁN RABADÁN, Teresa: "Las logias de Madrid del Gran Oriente Español en el siglo XIX". En José A. FERRER BENIMELI (coord.), La Masonería en Madrid y en España del siglo XVIII al XXI, Gobierno de Aragón, Zaragoza, 2004, pp. 51 -73. SAMPEDRO RAMO, Vicent: "La in- cidencia de la crisis masónica finisecular en las logias de la ciudad de Alicante". En José A. FERRER BENIMELI (coord.), La Masonería española entre Europa y América, Gobierno de Aragón, Zaragoza, 1995, pp. 85-105.

SAMPEDRO RAMO, Vicent: "La influencia del republicanismo en el nacimiento y desarrollo de la masonería alicantina en los primeros años de la Restauración". En José A. FERRER BENIMELI (coord.), La Masonería en Madrid y en España del siglo XVIII al XXI, Gobierno de Aragón, Zaragoza, 2004, pp. 285-324.

SÁNCHEZ FERRÉ, Pere: "Anticlericalismo y masonería en España". En José A. FERRER BENIMELI (coord.), Masonería y religión: convergencias, oposición, ¿̇incompatibilidad? Editorial Complutense, Madrid, 1996., pp. 271-288.

SANLLORENTE BARRAGÁN, Francisco: "Anticlericalismo, pacifismo y cuestión social en las logias del Gran Oriente Español (18901895)". En José A. FERRER BENIMELI(coord.), La Masonería española y la crisis colonial del 98, Gobierno de Aragón, Zaragoza, 1999, pp. 223-236.

USÓ ARNAL, Juan Carlos: "Católicos y masones en Castellón de la Plana: El Juicio promovido por el Gran Oriente Español contra los presbíteros D. Wenceslao Balaguer y D. Andrés Serrano y la constitución de la Liga Antimasónica". En el Boletín de la Sociedad Castellonen- 
se de Cultura, Tomo LIX, Edita Sociedad Castellonense de Cultura, Enero - Marzo de 1983, pp. 91-109.

USÓ ARNAL, Juan Carlos: "La masonería castellonense contemporánea". En José A. FERRER BENIMELIcoord.), La Masonería en la historia de España, Edita Diputación General de Aragón, Zaragoza, 1985, pp. 257-270.

VALÍN FERNÁNDEZ, Alberto: "La masonería, una discreta forma de sociabilidad democrática". En Alberto VALÍN FERNÁNDEZ (editor), La sociabilidad en la historia contemporánea, Editorial Duen de Bux, Ourense, 2001, pp. 74-96.

VICENTE y PALACIO, Antonio M.: "Grups Polítics i clase dirigent a Castelló de la Plana (1850-1875). Introducció a un estudi d'història local". Primer congrés d'estudis d'hitòria de la Plana, Diputación de Castellón, 1987, pp. 233-244.

VVAA, Isidro SÁNCHEZ SÁNCHEZ y Rafael VILLENA ESPINOSA: "Sociabilidad y masonería: conflictos en torno al Corazón de Jesús en el umbral del siglo XX". En José $A$. FERRER BENIMELI (coord.), La Masonería en la España del siglo XX. Universidad de Castilla La Mancha, Toledo, 1996, pp. 59-74.

VVAA, Ventura GAYETE, Empar EUGÈNIA: "Tres publicaciones y un debate: La bandera federal, La antorcha valentina y La verdad". En José A. FERRER BENIMELI (coord.), La Masonería en Madrid y en España del siglo XVIII al XXI, Gobierno de Aragón, Zaragoza, 2004, pp. 353-363.

\section{Libros}

VVAA: Elencos de fechas para la historia urbana de Castellón de la Plana. Sociedad Castellonense de Cultura, Castellón, 1993.

VVAA: España en sociedad. Las asociaciones a finales del siglo XIX. Grupo de Estudios de Asociacionismo y Sociabilidad. Servicio de Publicaciones de la Universidad de Castilla-La Mancha, Cuenca, 1998. VVAA: "Franc-maçonnerie et hitoire. Bilan et perspectives". Actas del coloquio internacional e interdisciplinar 14-16 noviembre 2001, Rouen. Christine Gaudin y Eric Saunier, coordinación. Publications des Universités de Rouen et du Havre, Roven, 2003.

VVAA: La masonería en la historia de España, J. A. Benimelli (coordinador). Gobierno de Aragón, Zaragoza, 1985.

VVAA: La sociabilidad en la historia contemporánea. Alberto Valín director. Duen de Bux, S.L., Ourense, 2001.

VVAA: Masonería y religión: convergencias, oposición, íncompatibilidad? José A. Ferrer Benimeli (coord.), Editorial Complutense, Madrid 1996.

ÁlVAREZ LÁZARO, Pedro: la masonería, escuela de formación del ciudadano. La educación interna de los masones españoles en el último 
tercio del siglo XIX. Publicaciones de la Universidad Pontificia Comillas, Madrid 1996.

ARCHILÉS CARDONA, Ferrán: Parlar en nom del poble. Cultura politica, discurs i mobilització social al republicanisme castellonenc (1891. 1909). Castelló d'Impressió, Castellón, 2002.

BADENES GASSET-RAMOS, Inmaculada, Fernando Gasset Lacasaña, biografía a política de un republicano (1861-1941), Tesis Doctoral dirigida por Rosa Monlleó, Universitat Jaume I, 2003.

BALBÁS, Juan A.: El libro de la provincia de Castellón. Primera Edición Imprenta de J. Armengot, C/ Enmedio 77, Castellón, 1892. Edición actual por Caja de ahorros y Monte de Piedad de Castellón, Editorial Confederación Española de Cajas de Ahorros, Castellón, 1987.

BLASCO CARRASCOSA, Joan Ángel: El krausime valencià. Institució Alfons el Magnánim, Valencia, 1982.

CAMPOS VILANOVA, Javier: Castellón 1881 - 1980 Editor I. Mora, Castellón, 1985. Cruz,

FERRER BENIMELli, José Antonio: La Masonería. Alianza Editorial, Madrid, 2005.

FERRER BENIMELI, José Antonio: La masonería española en el siglo XVIII. Siglo XXI editores, Madrid, 1986.
HERRÁlZ, Josep L. y REDÓ, Pilar: Republicanisme $i$ valencianisme (1868 - 1938): La familia Huguet. Publicaciones de la Universidad Jaime I, 1995.

IGNACIO CRUZ, J.: Masonería y educación en la II República Española. Instituto de Cultura "Juan Gil-Albert", Alicante, 1993.

LLANSOLA GIL, Gerard: Republicanisme, identitat popular i hegemonía municipal, Castelló de la Plana, 1913-1917. Publicaciones de la Universidad Jaime I, Castellón, 2006.

LÓPEZ CASIMIRO, Francisco: Masonería, prensa y política (Badajoz, 1875-1902). Universidad de Granada, Granada, 1992.

MARTí MARTíNEZ, Manuel: Cossieros i anticossieros. Burgesia i política local (Castelló, 1875-1891). Diputació Provincial de Castelló, Castellón, 1985.

PÉREZ ARRIBAS, Eduardo: Polítics i cacics a Castelló (1876-1901). Institut Valencià d'Estudis i Investigació, 1988.

PUIG PUIGCERVER, Ramón: Els corcs de la Restauració. Vinarós (1876-1923). Publicaciones de la Universidad Jaime I, Castellón, 2005.

REGUILLO SIMÓN, Germán: EI partido republicano de Castellón (1868-1936). Diputación de Castellón, Col.lecció Universitaria, Castellón, 2001. 
SALMÓN-MONVIOLA, Olivia: La de Castellón. 100 años de historia. palabra de paso - Identidades y Edita Cámara Oficial de Comercio, transmisión de la masonería de Ma- Industria y Navegación de Castedrid (1900-1936). Ediciones Idea, Colección Escuadra y Compás, Santa Cruz de Tenerife, 2008. llón, 2001.

SOUCY, Dominique: Masonería y nación. Redes masónicas y políticas en la construcción identitaria cubana (1811-1902). Ediciones Idea, Colección Escuadra y Compás, Santa Cruz de Tenerife, 2006. USÓ ARNAL, Juan Carlos: La masonería castellonense contemporánea (1874-1939), Tesis de Licenciatura dirigida por Joan Brines Blasco, Universidad de Valencia, Facultad de Geografía e Historia, Valencia, VALLS TORLÁ, Javier: La Cámara de 1982.

Comercio, Industria y Navegación 


\section{Cuadro Logias masónicas en Castellón a finales del siglo XIX}

\begin{tabular}{|c|c|c|c|}
\hline Nombre & Población & Clasif́cación & Obediencia \\
\hline $\begin{array}{c}\text { Casturolense, } \\
n^{\circ} 36\end{array}$ & Castellón & Taller & Gran Oriente Nacional de España \\
\hline Justicia, $n^{\circ} 21$ & Castellón & Taller & Gran Oriente de España \\
\hline $\begin{array}{c}\text { Tres Estrella, } \mathrm{n}^{\circ} \\
135\end{array}$ & Castellón & Taller & Gran Oriente Nacional de España \\
\hline $\begin{array}{l}\text { Tres Estrella, } \\
N^{\circ} 28\end{array}$ & Castellón & Capítulo & Gran Oriente Nacional de España \\
\hline $\begin{array}{c}\text { Integridad, } \mathrm{n}^{\circ} \\
28\end{array}$ & Castellón & Capítulo & Gran Oriente Nacional de España \\
\hline $\begin{array}{l}\text { Progreso, } n^{\circ} \\
213\end{array}$ & Castellón & Taller & Gran Oriente Nacional de España \\
\hline $\begin{array}{c}\text { Esperanza V, } n^{\circ} \\
214\end{array}$ & Castellón & Taller & Gran Oriente Nacional de España \\
\hline $\begin{array}{l}\text { Capítulo } \\
\text { Provincial de } \\
\text { Castellón }\end{array}$ & & & Gran Oriente Nacional de España \\
\hline $\begin{array}{l}\text { Logia Provincial } \\
\text { de Castellón }\end{array}$ & & & Gran Oriente Nacional de España \\
\hline Verdad, $n^{\circ} 182$ & Castellón & Taller & Gran Oriente de España \\
\hline 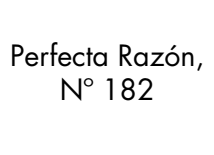 & Castellón & Taller & $\begin{array}{l}\text { Gran Oriente de España/ Gran } \\
\text { Oriente Nacional de España del } \\
\text { Vizconde de Ros/Gran Oriente } \\
\text { Español }\end{array}$ \\
\hline Castalia & Castellón & Taller & Gran Oriente Español \\
\hline Razón & Castellón & Capítulo & $\begin{array}{c}\text { Gran Oriente Nacional de España } \\
\text { del Vizconde de Ros/Gran Oriente } \\
\text { Español }\end{array}$ \\
\hline
\end{tabular}




\section{Fecha aparición}

8 de junio de 1870

\section{Fecha desaparición}

Aparece en un listado de su

Obediencia como logia en activo en 1876, no hay más referencias

Aparece en un listado de su Obediencia como logia en activo

el 1 de junio de 1873, no hay más referencias

Siguió funcionando por lo menos hasta principios de 1892

Hasta la aparición del Capítulo Integridad, $\mathrm{n}^{\circ} 28$

El último cuadro lógico conservado es el de 31 de diciembre de 1895, funcionando posiblemente hasta el cierre de su Obediencia a finales de 1896

El último cuadro lógico conservado es el de enero de 1895, funcionando posiblemente hasta el cierre de su

Obediencia a finales de 1896

En activo por lo menos hasta principios de 1892

4 de julio de 1886

Anterior al 14 de diciembre de 1879, sin poder precisarla

\section{5 de marzo de 1893}

Al seguir funcionando Progreso y Capítulo Integridad debió seguir funcionando posiblemente hasta el 15 de marzo de 1893 cierre de su Obediencia a finales de 1896

Entre finales de 1887 e inicios de 1888

Sin precisar, entre junio de 1880 y enero de 1883

31 de enero de 1888

Inicios de 1890

En funcionamiento por lo menos hasta abril de 1892

Última aparición en el Boletín de su Obediencia el 4 de febrero de 1891, debiendo funcionar por lo menos ese año 